\title{
VALIDITY OF DIAGNOSTIC PURE-TONE AUDIOMETRY WITHOUT A SOUND-TREATED ENVIRONMENT IN OLDER ADULTS
}

\section{Felicity Maclennan-Smith ${ }^{1}$, De Wet Swanepoel ${ }^{1,2,3,4}$, James W. Hall III ${ }^{1}$}

1. Department of Communication Pathology, University of Pretoria, South Africa

2. Callier Center for Communication Disorders, University of Texas at Dallas, USA

3. Ear Sciences Centre, School of Surgery, the University of Western Australia, Nedlands, Australia

4. Ear Science Institute Australia, Subiaco, Australia

\section{Corresponding author:}

Prof. De Wet Swanepoel

Department of Communication Pathology

University of Pretoria

C/o Lynnwood \& University Roads

Hatfield, 0002

South Africa

Dewet.swanepoel@up.ac.za

\section{ABSTRACT}

Objective: To investigate the validity of diagnostic pure-tone audiometry in a natural environment using a computer-operated audiometer with insert earphones covered by circumaural earcups incorporating real-time monitoring of environmental noise. Design: A within-subject repeated measures design was employed to compare air (250 to $8000 \mathrm{~Hz}$ ) and bone $(250$ to $4000 \mathrm{~Hz}$ ) conduction pure-tone thresholds measured in retirement facilities with thresholds measured in a sound-treated booth. Study sample: 147 adults (average age $76 \pm$ 5.7 years) were evaluated. Pure-tone averages were normal in $59 \%$, mildly (>40 dB) elevated in $23 \%$ and moderately $(>55 \mathrm{~dB}$ ) elevated in $6 \%$ of ears. Results: Air-conduction 
thresholds $(n=2259)$ corresponded within 0 to $5 \mathrm{~dB}$ in $95 \%$ of all comparisons between the two test environments. Bone-conduction thresholds $(n=1669)$ corresponded within 0 to $5 \mathrm{~dB}$ in $86 \%$ of comparisons. Average threshold differences (-0.6 to 1.1) and standard deviations (3.3 to 5.9) were within typical test-retest reliability limits. Thresholds recorded showed no statistically significant differences (Paired Samples T-test:p>0.01) except at $8000 \mathrm{~Hz}$ in the left ear. Conclusion: Valid diagnostic pure-tone audiometry can be performed in a natural environment with recently developed technology, offering the possibility of access to diagnostic audiometry in communities where sound-treated booths are unavailable.

Key Words: Audiometry; air conduction; bone conduction; computer-operated audiometer; ambient noise; natural environment; sound booth

\section{INTRODUCTION}

Pure-tone audiometry has remained the unequivocal gold standard for assessment of hearing since its widespread inception as a clinical tool more than six decades ago. A prerequisite for reliable audiometry measures is a controlled test environment with sufficiently low levels of ambient noise to ensure background noise does not mask hearing thresholds as low as $0 \mathrm{~dB} \mathrm{HL}$. An adequate test environment is typically achieved by employing audiometric test booths or sound-treated rooms that are specially constructed to provide a sound-isolated environment for testing. Standards of international and national bodies such as the American National Standards Institute (ANSI) and the South African National Standards (SANS) require that ambient noise levels in audiometric test rooms be sufficiently low so as to ensure that hearing thresholds are not artificially elevated.

The compliance of audiometric booths with permissible ambient noise levels specified by ANSI (ANSI S3.1-1999(R2008)) has however been surprisingly poor. A study by Frank and Williams (1993) measured noise levels in 136 audiometric test rooms in various audiological facilities. For air-conduction testing using supra-aural earphones only $50 \%$ of booths had 
sufficiently low ambient noise levels for testing 250 to $8000 \mathrm{~Hz}$ (ANSI S3.1-1999). For boneconduction testing with ears uncovered, permissible ambient noise levels were sufficient in only $14 \%$ of booths for testing 250 to $8000 \mathrm{~Hz}$. In a similar study conducted on 490 singlewalled prefabricated audiometric booths used for industrial testing only $33 \%$ met the ANSI (ANSI S3.1-1999) minimum permissible noise levels (Frank \& Williams, 1994). Another compliance concern related to audiometric booths is that they are to be certified annually during a "typical" working day to ensure compliance with permissible ambient noise levels standards (ANSI, 1999; OSHA, 1983). Transient sources of noise can however vary during a "typical" or "atypical" day or days and may affect test results without the clinician's knowledge (Frank \& Williams, 1993; Frank \& Williams, 1994).

Apart from compliance concerns, audiometric sound booths and sound-treated rooms have other limitations related to expense and mobility. The booths appropriate for diagnostic audiometry are usually more costly than the audiometer, especially for double-walled rooms. Furthermore because of their size and weight, sound-treated booths almost always remain in one location, and cannot be transported to test sites. Mobile booths are used for occupational screening purposes and require calibration after each relocation for compliance with specified standards (ANSI, 1999; OSHA, 1983). The use of mobile booths is cumbersome and often not financially viable for servicing patients, who, in need of diagnostic audiometry, are unable to attend audiological centres (e.g. bed ridden patients or patients in retirement homes). The expense of sound-treated booths and their lack of mobility hinder the delivery of diagnostic audiometry services in lower-income developing countries where they are often unavailable or restricted to large cities (Swanepoel, Clark et al. 2010; Swanepoel, Olusanya \& Mars, 2010). The challenge of accessing a proper sound environment is also particularly pertinent for the growing field of telemedicine applications in audiometry which demonstrates the potential to provide services in remote and underserved regions (Swanepoel, Clark et al. 2010; Swanepoel, Olusanya \& Mars, 2010). 
Owing to the above limitations and challenges related to sound-booths, alternate passive and active noise reduction approaches in headphone sets have been investigated to allow for sufficient attenuation for reliable testing down to $0 \mathrm{~dB}$ HL. Supra-aural earphones by themselves provide limited attenuation of ambient noise, especially in lower frequencies (Berger \& Killion, 1989; Arlinger, 1986; Frank \& Wright, 1990). The use of supra-aural earphones within noise-reducing enclosures has been evaluated in an attempt to improve attenuation to allow for compliant testing in environments with high ambient noise levels. Although these provide additional attenuation, they are insufficient for diagnostic testing down to $0 \mathrm{~dB}$, especially at lower frequencies (Frank, Greer \& Magistro, 1997). In addition, thresholds are further elevated with poorer test-retest reliability than regular supra-aural earphones (Frank, Greer \& Magistro, 1997).

Insert earphones are recommended as a more effective way of reducing ambient noise levels for compliant testing (Frank, Greer \& Magistro, 1997; Berger \& Killion, 1989). According to Berger and Killion (1989), insert earphones that are properly placed within the external ear canal can provide 30 to $40 \mathrm{~dB}$ of attenuation of ambient noise which is sufficient to allow for testing down to audiometric zero across the frequency range of 125 to $8000 \mathrm{~Hz}$ in typical office noise environments. The attenuation with insert earphones may be prone to some variability owing to insertion depth even though hearing thresholds measured with insert earphones are consistent (Berger \& Killion, 1989; Clark \& Roeser, 1988). Adding earmuffs or circumaural earcups over the insert earphones provides a further increase in attenuation (Berger, 1983; Berger, Kieper \& Gauger 2003). Active noise reduction headphone technology may also be included in these circumaural earcups covering insert earphones. Bromwich et al. (2008) used a combination of circumaural active noise cancellation earphones covering insert earphones and demonstrated that with $30 \mathrm{~dB}$ SPL ambient noise levels in the sound field no shifts in hearing thresholds were noticed across frequencies $(250-4000 \mathrm{~Hz})$. Ambient noise exceeding this level can however result in 
threshold elevations (Bromwich et al. 2008) and the active circuitry may raise the noise floor to unacceptable levels.

The benefit of increased attenuation using insert earphones covered with circumaural earcups is therefore negated if the ambient environmental noise is not monitored continually to ensure compliance while each threshold is measured. The current study investigated the validity of hearing threshold estimation in a natural environment with a recently validated audiometer (Swanepoel \& Biagio, 2011) utilizing insert earphones covered by circumaural earcups that incorporate external microphones monitoring environmental noise levels during testing.

\section{METHOD}

This repeated-measure within-subject study was approved by the institutional Ethics Committee of the University of Pretoria in South Africa and all subjects provided informed consent prior to participation.

\section{Subjects}

A sample of 147 elderly subjects (57\% female) with an average age of 75.8 years (SD 5.7; Range 65 -94) was recruited from four retirement homes in the Western Cape, South Africa, for diagnostic pure-tone audiometry evaluations conducted first at the retirement home in a room provided by the facility and followed by the same evaluation at an audiology clinic in an audiometric boothIndividual ears were included in the study when at both evaluations an intact tympanic membrane was otoscopically visible in combination with a normal Type $A$ tympanogram. These criteria excluded from the study six ears with possible transitory middle ear pathology. In cases of excessive cerumen this was removed by the audiologist before testing. In total, $59 \%$ of the ears included in the study $(n=288)$ from the 147 subjects demonstrated pure-tone average $(500,1000,2000$ and $4000 \mathrm{~Hz})$ thresholds of $25 \mathrm{~dB}$ or greater. Nearly a quarter (23\%) of ears had pure-tone averages of greater than $40 \mathrm{~dB}$ and $6 \%$ had pure-tone averages of greater than $55 \mathrm{~dB}$. 


\section{Equipment}

Tympanometry was conducted as part of the screening procedure using an Interacoustics MT 10 handheld impedance audiometer/middle ear analyser employing a $226 \mathrm{~Hz}$ probe tone. The audiometer used was a KUDUwave 5000 (GeoAxon, Pretoria, South Africa), a Type 2 Clinical Audiometer (IEC 60645-1/2) that was software controlled and operated via a Notebook (Acer Travelmate 2492 running Windows XP). The audiometer hardware was encased in each circumaural earcup and was powered by a USB cable plugged into the Notebook. The transducers included embedded custom insert earphones, which were covered by the circumaural cups after insertion. The insert earphone frequency response approximated that of the ER3A within $1 \mathrm{~dB}$ across test frequencies allowing for the use of the international insert earphone standard (ISO 389-2, 1994) for calibration. A B-71 bone oscillator (Kimmetrics, Smithsburg, Md.) was placed on the forehead with a standard adjustable spring headband held in place on the center of the circumaural headband with a screw fitting (Figure 1).

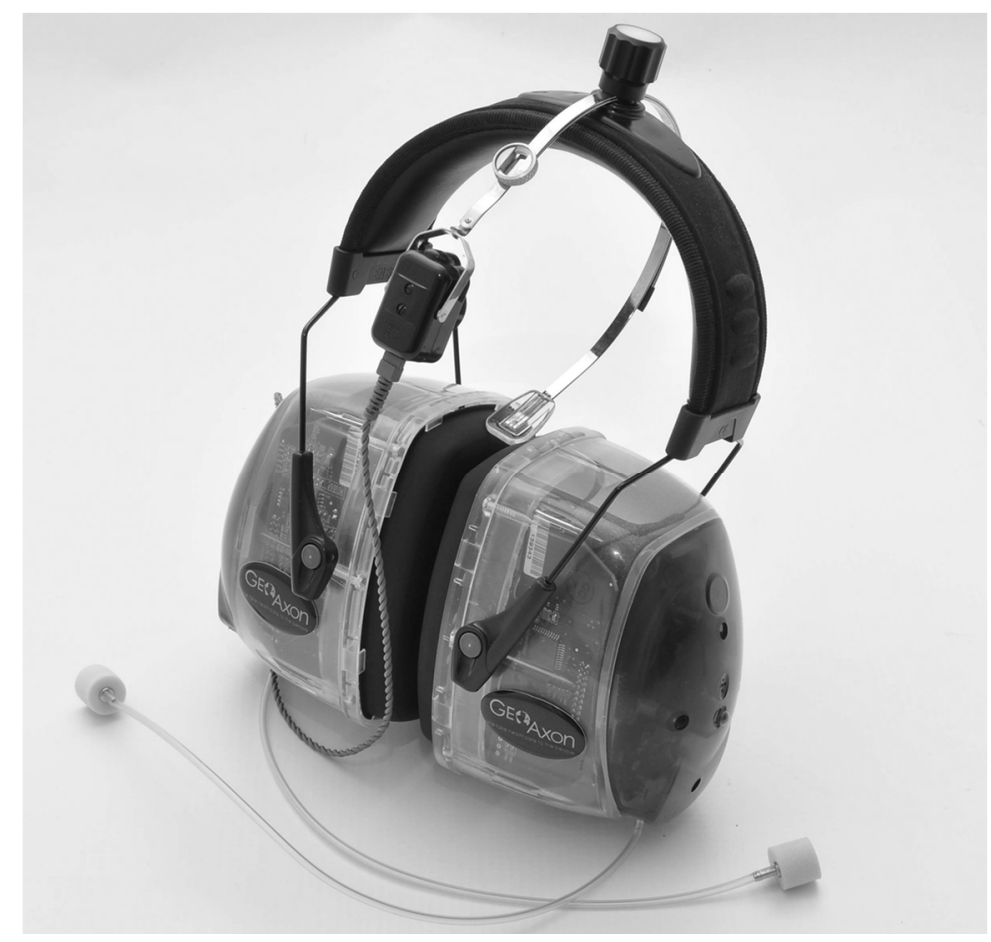

Figure 1. KUDUwave audiometer showing insert earphones, circumaural earcups housing audiometers and forehead bone conductor mounted centrally on headband 
The audiometer had two microphones on the circumaural earcup that monitored the environmental noise in octave bands during testing and was visually represented in real-time on the software (Figure 2). The noise-monitoring function of the KUDUwave used low-pass $(<125 \mathrm{~Hz})$, seven single octave band-pass $(125,250,500,1000,2000,4000$ and $8000 \mathrm{~Hz})$ and high-pass $(>8000 \mathrm{~Hz}$ ) filters to separate the incoming sound. The output of these filters was monitored in real-time and the peak value calculated and compared to a proprietary volume unit ballistic profile and the higher of the two passed to the user interface software (eMOYO) every $100 \mathrm{~ms}$. The filters had a stop-band attenuation of $90 \mathrm{~dB}$ and pass-band

\section{Jane Smith}

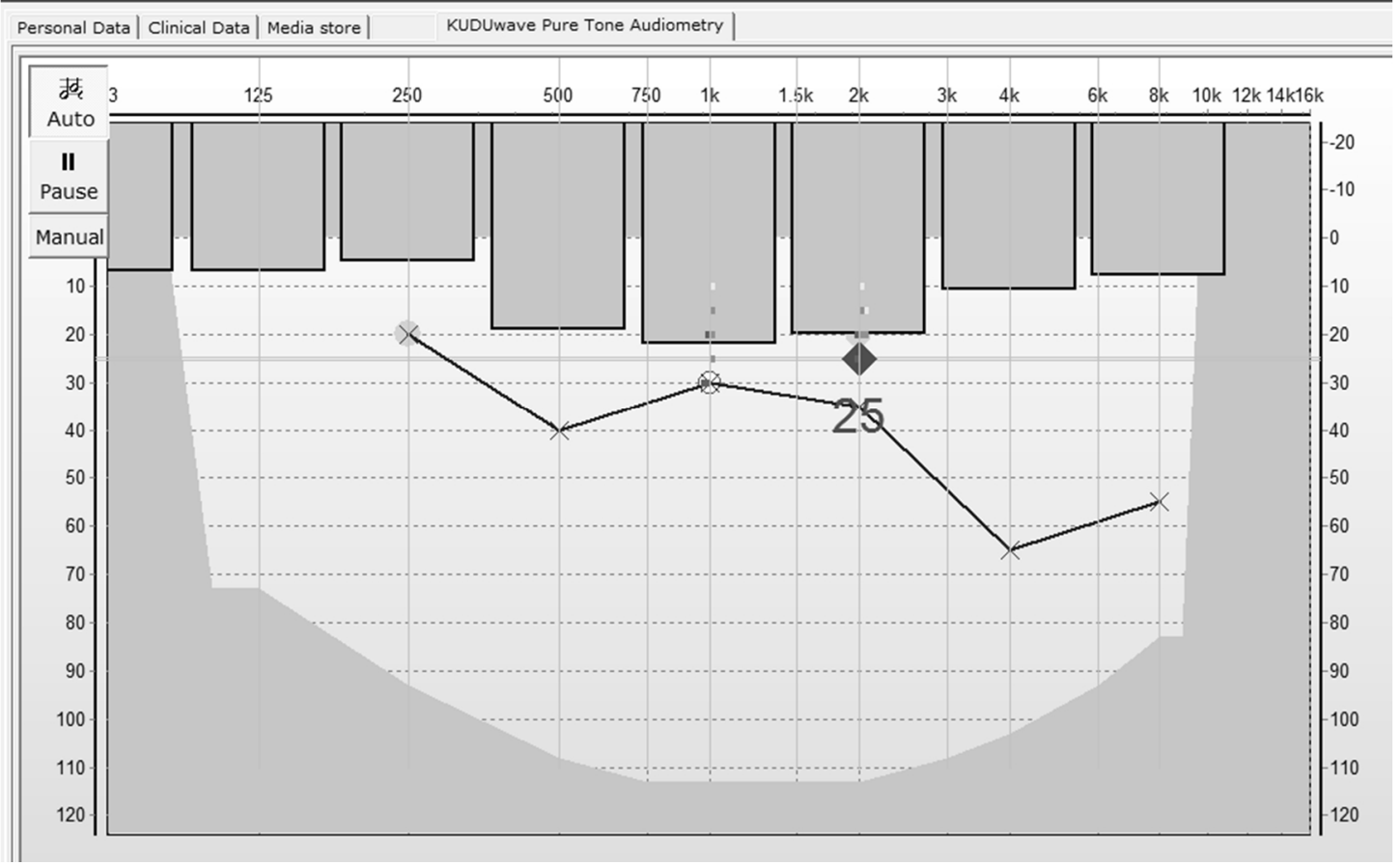

Figure 2. Screenshot of KUDUwave software demonstrating real-time monitoring of ambient noise levels while establishing thresholds

ripple of $0.003 \mathrm{~dB}$. The environment-monitoring microphones incorporated in the headset were verified using an input signal of $1 \mathrm{kHz}$ at $94 \mathrm{~dB}$ SPL to show a maximum variation of 3.6 $\mathrm{dB}$ across microphones. Calibration of the microphones was based on an effective attenuation level which was determined using expert subjects with normal hearing sensitivity. Pure tones were presented at irregular intervals to the test subjects at an intensity level 10 
$\mathrm{dB}$ higher than the threshold of the test ear for frequencies in each octave band as well as the inter-octave frequencies $(125$ to $8000 \mathrm{~Hz})$. The insert earphones were placed in the ear canals with the $12 \mathrm{~mm}$ foam tip completely fitted into the canal and covered by the circumaural cups of the KUDUwave audiometer. Continuous narrowband noise was presented through free-field speakers situated at 45 degrees 1 meter in front of the subject. The intensity of the noise was slowly increased until the pure tones could not be detected. The average of these levels at each frequency and per ear was used as the effective attenuation level for each frequency.

A response button was connected to the KUDUwave device to record patient responses to stimuli and to document response times. The audiometer was calibrated prior to commencement of the study using an 824 Type 1 sound level meter (Larson Davis, Provo, Utah) with a G.R.A.S. (Holte, Denmark) IEC 711 coupler for insert earphones and an AMC493 Artificial Mastoid on an AEC101 coupler (Larson Davis) with 2559 1/2 inch microphone for the Radioear B-71 bone oscillator. Insert earphones were calibrated in accordance with ISO 389-2 and the bone oscillator according to ISO 389-3. Testing in the audiometric booth was conducted in a single-walled audiometric booth adhering to ambient noise levels specified by ANSI (ANSI S3.1-1999(R2008)) for evaluating hearing down to $0 \mathrm{~dB}$ $\mathrm{HL}$ from 250 to $8000 \mathrm{~Hz}$.

\section{Procedures}

Subjects were tested twice with diagnostic air $(250,500,1000,2000,3000,4000,6000$, $8000 \mathrm{~Hz}$ ) and bone-conduction (250, 500, 1000, 2000,3000, $4000 \mathrm{~Hz}$ ) pure-tone audiometry by the same experienced audiologist using the same audiometer. Testing sequence was held constant, intentionally confining procedure variability for the best comparison between the two test environments. In all cases, the initial test was conducted in a natural environment provided by the retirement home facility, and constituted a quiet furnished room. Conducting the initial test in the natural environment limited travelling costs and 
inconvenience in the event that a respondent proved not to meet the selection criteria. The second evaluation was conducted with the subject in a certified audiometric booth at an audiology clinic. Initial test results were not visible to the audiologist during the second evaluation, nor were they accessed prior to the test in the booth. The average time interval between tests was 6.4 ( $\pm 6.2 \mathrm{SD}$ ) days with the longest period being 42 days. An otoscopic examination and tympanometry were conducted prior to each evaluation to confirm the absence of any transient middle ear influences before inclusion in the study.

Air-conduction pure tones were delivered via deeply inserted insert foam tips covered by the circumaural earcups of the audiometer for additional attenuation (insert earphone and circumaural earcup attenuation). In the small number of cases where the $12 \mathrm{~mm}$ foam tips could not be fully inserted, such as in the presence of stenosis, they were placed as deeply as possible into the ear canals. Berger et al,. (2003) reported average attenuation for deeply inserted insert foam plugs covered by circumaural earphones. This is similar to the current study's double attenuation of $57,62,49,40,50$ and $50 \mathrm{~dB}$ for 250, 500, 1000, 2000, 4000 and $8000 \mathrm{~Hz}$, respectively. These attenuation values exceed those of typical transportable sound-treated booths (Franks, 2001). Forehead placement bone-conduction audiometry was conducted with both ears occluded by the deep insertion of the earphones. Placement of the insert earphones was deep with the foam tip inserted completely into the canal to improve the attenuation of ambient noise (Berger \& Killion, 1989; Berger, 1983; Berger, Kieper \& Gauger 2003) and to minimize the occlusion effect. Placing insert earphones down to the bony part of the ear canal reduces the occlusion effect allowing for bone-conduction evaluation with occluded ears (Dean \& Martin, 2000; Stenfelt \& Goode, 2005; Swanepoel \& Biagio, 2011). Deep insertion required removal of cerumen by the audiologist in $24.5 \%$ of the subjects prior to their inclusion in this study.

Verbal instructions were provided in either English or Afrikaans to ensure that the participant demonstrated an understanding of the test procedures. Subject responses with a patient 
response button allowed for recording reaction times for true positive responses within 1.5 seconds after stimulus presentation. Thresholds were measured using a routine modified 10 $\mathrm{dB}$ descending and $5 \mathrm{~dB}$ ascending method (modified Hughson-Westlake method) commencing at $1000 \mathrm{~Hz}$ at $40 \mathrm{~dB} \mathrm{HL}$ in the left ear and proceeding to the lower frequencies before recording thresholds at high frequencies. In the absence of a response at $40 \mathrm{~dB} H \mathrm{H}$, the intensity was increased in steps of $10 \mathrm{~dB}$ until a response was noted from where the bracketing method recommenced. Masking of $30 \mathrm{~dB}$ above the air-conduction threshold of the non-test ear commenced for air-conduction audiometry when the thresholds in test and non-test ears differed by $75 \mathrm{~dB}$ or more at frequencies of $1000 \mathrm{~Hz}$ and less and $50 \mathrm{~dB}$ or more at frequencies above $1000 \mathrm{~Hz}$. A continuous contralateral effective masking level of 20 $\mathrm{dB}$ above the air-conduction threshold of the non-test ear was used for the forehead boneconduction audiometry (ASHA, 2005).

Average noise levels recorded (over a 30 minute period) with a Type 1 sound level meter in two of the retirement homes showed average noise levels of 46.5 and $53.6 \mathrm{dBA}$ as opposed to $21.2 \mathrm{dBA}$ in the sound-booth environment. The KUDUwave software actively monitored ambient noise levels across octave bands throughout the test procedures in both test environments. Whenever the noise exceeded the maximum ambient noise level allowed for establishing a threshold as indicated by the effective attenuation level in the KUDUwave software, the audiologist waited for the transient noise to abate or continued testing at other frequencies. Thresholds were evaluated down to a minimum of $0 \mathrm{~dB} H \mathrm{HL}$

\section{Analysis}

The threshold data for air-conduction and bone-conduction testing in the two environments were analysed descriptively with average differences and absolute average differences presented with respective distributions. Correspondence of thresholds between the natural and clinical environment was described in percentages and with 95\% Confidence Intervals. A 
Paired Samples T-test with the significance level at $1 \%$ was used to determine whether hearing thresholds differed significantly between natural and clinical environments.

\section{RESULTS}

Table 1. Difference in air conduction thresholds recorded in the natural and audiometric booth environment (Thresholds recorded in the booth subtracted from those recorded in the natural environment)

\begin{tabular}{|c|c|c|c|c|c|c|c|c|}
\hline Freq $(\mathrm{Hz})$ & 250 & 500 & 1000 & 2000 & 3000 & 4000 & 6000 & 8000 \\
\hline \multicolumn{9}{|c|}{ Left AC Difference(Natural \& Booth) } \\
\hline$n$ & 143 & 143 & 143 & 143 & 143 & 143 & 139 & 126 \\
\hline Ave & 0.0 & 0.1 & 0.2 & 0.1 & -0.6 & -0.4 & 0.0 & 1.1 \\
\hline$S D$ & 5.4 & 4.3 & 3.6 & 3.5 & 3.3 & 3.4 & 3.6 & 4.6 \\
\hline $95 \% \mathrm{Cl}$ & $-0.8 ; 0.9$ & $-0.5 ; 0.9$ & $-0.3 ; 0.9$ & $-0.4 ; 0.7$ & $-1.2 ; 0.1$ & $-1.0 ; 0.1$ & $-0.7 ; 0.5$ & $0.3 ; 1.9$ \\
\hline $\pm 5 d B \%$ & 87 & 92 & 97 & 98 & 99 & 97 & 97 & 94 \\
\hline $\pm 10 d B \%$ & 97 & 99 & 100 & 100 & 100 & 100 & 100 & 98 \\
\hline \multicolumn{9}{|c|}{ Right AC Difference (Natural \& Booth) } \\
\hline$n$ & 145 & 145 & 145 & 144 & 143 & 143 & 140 & 131 \\
\hline Ave & -0.3 & 0.1 & -0.3 & 0.1 & -0.3 & -0.3 & -0.2 & 0.6 \\
\hline$S D$ & 5.9 & 3.9 & 3.6 & 4.0 & 3.9 & 3.5 & 3.9 & 4.7 \\
\hline $95 \% \mathrm{Cl}$ & $-1.3 ; 0.6$ & $-0.6 ; 0.7$ & $-0.9 ; 0.3$ & $-0.6 ; 0.8$ & $-1.0 ; 0.3$ & $-0.8 ; 0.3$ & $-0.8 ; 0.5$ & $-0.2 ; 1.5$ \\
\hline $\pm 5 d B \%$ & 86 & 96 & 97 & 96 & 95 & 99 & 97 & 88 \\
\hline $\pm 10 \mathrm{~dB} \%$ & 96 & 100 & 99 & 99 & 100 & 100 & 99 & 100 \\
\hline
\end{tabular}


Average air-conduction threshold differences between the natural environment and audiometric booth testing (Table 1) were between -0.6 and $1.1 \mathrm{~dB}$ with standard deviations of between 3.3 and $5.9 \mathrm{~dB}$ across frequencies and left and right ears. Average bone-conduction threshold differences between the natural environment and audiometric booth testing (Table 2) were between -0.6 and $1.3 \mathrm{~dB}$ with standard deviations of between 4.0 and $7.5 \mathrm{~dB}$ across

Table 2. Difference in bone conduction thresholds recorded in the natural and audiometric booth environment (Thresholds recorded in the booth subtracted from those recorded in the natural environment)

\begin{tabular}{|c|c|c|c|c|c|c|}
\hline Freq $(\mathrm{Hz})$ & 250 & 500 & 1000 & 2000 & 3000 & 4000 \\
\hline \multicolumn{7}{|c|}{ Left BC Difference (Natural \& Booth) } \\
\hline$n$ & 140 & 139 & 142 & 141 & 135 & 132 \\
\hline Ave & 0.7 & 0.8 & 0.1 & 0.6 & -0.6 & -0.3 \\
\hline$S D$ & 5.9 & 5.7 & 7.5 & 4.1 & 4.0 & 4.4 \\
\hline $95 \% \mathrm{Cl}$ & $-0.3 ; 1.7$ & $-0.2 ; 1.7$ & $-1.2 ; 1.3$ & $-0.1 ; 1.2$ & $-1.3 ; 0.1$ & $-1.1 ; 0.5$ \\
\hline $\pm 5 d B \%$ & 86 & 85 & 73 & 93 & 93 & 92 \\
\hline $\pm 10 \mathrm{~dB} \%$ & 94 & 97 & 90 & 99 & 100 & 99 \\
\hline \multicolumn{7}{|c|}{ Right BC Difference (Natural \& Booth) } \\
\hline$n$ & 142 & 141 & 143 & 142 & 136 & 136 \\
\hline Ave & -0.2 & 1.3 & 0.4 & 0.2 & -0.1 & -0.3 \\
\hline$S D$ & 6.3 & 6.0 & 6.2 & 4.1 & 4.7 & 5.1 \\
\hline $95 \% \mathrm{Cl}$ & $-1.2 ; 0.9$ & $0.3 ; 2.3$ & $-0.6 ; 1.4$ & $-0.5 ; 0.9$ & $-0.9 ; 0.7$ & $-1.2 ; 0.5$ \\
\hline $\pm 5 d B \%$ & 86 & 77 & 78 & 94 & 91 & 88 \\
\hline $\pm 10 d B \%$ & 94 & 96 & 95 & 99 & 99 & 99 \\
\hline
\end{tabular}


Table 3. Difference in air and bone conduction thresholds $\leq 25 \mathrm{~dB}$ and $>25 \mathrm{~dB}$ recorded in the natural and audiometric booth environment (Thresholds recorded in the booth subtracted from those recorded in the natural environment)

\begin{tabular}{lllllllll}
\hline Freq $(\mathrm{Hz})$ & 250 & 500 & 1000 & 2000 & 3000 & 4000 & 6000 & 8000
\end{tabular}

AC Thresholds $\leq 25 \mathrm{~dB}$ difference (Natural \& Booth)

\begin{tabular}{|c|c|c|c|c|c|c|c|}
\hline$n$ & 209 & 208 & 177 & 133 & 96 & 72 & 45 \\
\hline Ave & 0.3 & 0.5 & 0.0 & 0.3 & -0.1 & -0.5 & 0.4 \\
\hline$S D$ & 5.3 & 4.0 & 3.6 & 3.7 & 3.4 & 3.9 & 3.2 \\
\hline $\pm 5 d B \%$ & 88 & 94 & 95 & 97 & 99 & 96 & 100 \\
\hline
\end{tabular}

AC Thresholds > 25 dB difference (Natural \& Booth)

$\begin{array}{lllllllll}\boldsymbol{n} & 79 & 80 & 111 & 154 & 190 & 214 & 234 & 242 \\ \text { Ave } & -1.2 & -0.8 & 0.0 & -0.1 & -0.7 & -0.3 & -0.3 & 0.7 \\ \mathbf{S D} & 6.1 & 4.3 & 3.5 & 3.8 & 3.7 & 3.3 & 3.8 & 4.7 \\ \mathbf{\pm} & & & & & & & & \end{array}$

BC Thresholds $\leq 25 \mathrm{~dB}$ difference (Natural \& Booth)

$\begin{array}{lcccccc}\boldsymbol{n} & 273 & 243 & 212 & 146 & 111 & 100 \\ \text { Ave } & 0.5 & 1.4 & 1.2 & 0.7 & -0.3 & -0.2 \\ \text { SD } & 5.7 & 5.9 & 6.4 & 3.8 & 4.3 & 4.3 \\ & & & & & & \\ \mathbf{\pm} & 86 & 79 & 75 & 95 & 95 & 91\end{array}$

BC Thresholds > 25 dB difference (Natural \& Booth)

\begin{tabular}{|c|c|c|c|c|c|c|}
\hline$n$ & 9 & 37 & 73 & 137 & 160 & 168 \\
\hline Ave & -6.7 & -1.8 & -2.6 & 0.0 & -0.4 & -0.4 \\
\hline$S D$ & 13.2 & 4.3 & 7.6 & 4.4 & 4.5 & 5.1 \\
\hline $\pm 5 d B \%$ & 78 & 92 & 74 & 92 & 91 & 89 \\
\hline
\end{tabular}


frequencies and left and right ears. Differences in the natural and audiometric booth environments across ears and frequencies were within $\pm 5 \mathrm{~dB}$ for $95 \%$ of air-conduction thresholds $(n=2259)$ and $86 \%$ of bone-conduction thresholds $(n=1669)$. Bone-conduction thresholds corresponded within 0 to $10 \mathrm{~dB}$ in $97 \%$ of cases. Approximately half of the airconduction (53\%) and bone- conduction (51\%) thresholds showed no change between test environments.

Normal hearing thresholds $(\leq 25 \mathrm{dBHL})$ and elevated thresholds $(>25 \mathrm{dBHL})$ as shown in Table 3, demonstrated similar average threshold differences and standard deviations. The average absolute difference for air-conduction thresholds was $2.7 \mathrm{~dB}( \pm 3.2 \mathrm{SD})$ and $2.7 \mathrm{~dB}$ ( \pm 3.1 SD) for normal $(\leq 25 \mathrm{dBHL})$ compared to elevated $(>25 \mathrm{dBHL})$ threshold comparisons respectively. Air-conduction thresholds in the natural and audiometric booth corresponded within $5 \mathrm{~dB}$ or less of each other in $94.1 \%$ of cases for normal hearing thresholds $(\leq 25 \mathrm{dBHL})$ compared to $94.9 \%$ for elevated thresholds (>25 dBHL). The average absolute difference for bone-conduction thresholds was $3.4 \mathrm{~dB}( \pm 4.2 \mathrm{SD})$ and $3.4 \mathrm{~dB}( \pm 4.3 \mathrm{SD})$ for normal $(\leq 25$ $\mathrm{dBHL}$ ) compared to elevated ( $>25 \mathrm{dBHL}$ ) threshold comparisons respectively. Boneconduction thresholds in the natural environment and audiometric booth corresponded within $10 \mathrm{~dB}$ or less of each other in $96.7 \%$ of cases for normal hearing thresholds ( $\leq 25 \mathrm{dBHL}$ ) compared to $96.9 \%$ for elevated thresholds ( $>25 \mathrm{dBHL})$.

The average absolute difference between thresholds recorded in the natural and audiometric booth environments for air conduction (Figure 3) was $2.7 \pm 3.1 \mathrm{~dB}$ and for bone conduction (Figure 4) was $3.4 \pm 4.3 \mathrm{~dB}$, across all frequencies. The average absolute differences (Table 4) in air-conduction thresholds varied between 2.0 and $3.6 \mathrm{~dB}$ across frequencies with standard deviations between 2.6 and $4.0 \mathrm{~dB}$. Bone-conduction average absolute differences varied between 2.6 and 5.2 with standard deviations between 3.2 and 5.3 . 


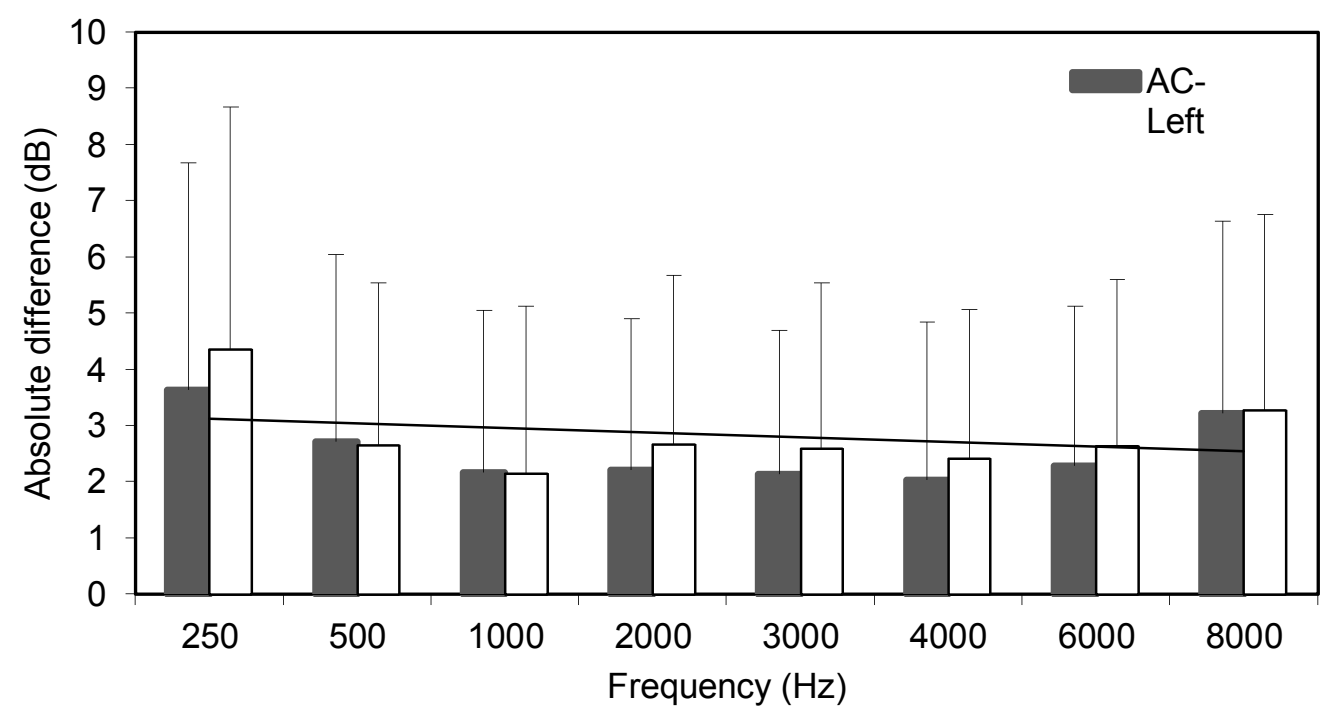

Figure 3. Average absolute difference between air conduction thresholds recorded in the natural and audiometric booth environment (error bars $=1$ SD)

Table 4. Absolute difference in air and bone conduction thresholds recorded in the natural and audiometric booth environment (Left \& Right ears combined)

\begin{tabular}{|c|c|c|c|c|c|c|c|c|}
\hline Freq $(\mathrm{Hz})$ & 250 & 500 & 1000 & 2000 & 3000 & 4000 & 6000 & 8000 \\
\hline \multicolumn{9}{|c|}{ AC Threshold Correlation (Natural \& Booth) } \\
\hline Ave (Abs) & 3.6 & 2.7 & 2.2 & 2.2 & 2.1 & 2.0 & 2.3 & 3.2 \\
\hline$S D$ & 4.0 & 3.3 & 2.9 & 2.7 & 2.6 & 2.8 & 2.8 & 3.4 \\
\hline$n$ & 294 & 294 & 294 & 293 & 292 & 292 & 284 & 262 \\
\hline
\end{tabular}

BC Threshold Correlation (Natural \& Booth)

$\begin{array}{lrrrrrr}\text { Ave (Abs) } & 2.8 & 3.8 & 5.2 & 2.6 & 2.7 & 2.9 \\ \text { SD } & 5.3 & 4.3 & 5.3 & 3.2 & 3.3 & 3.3 \\ n & 288 & 286 & 291 & 289 & 276 & 273\end{array}$




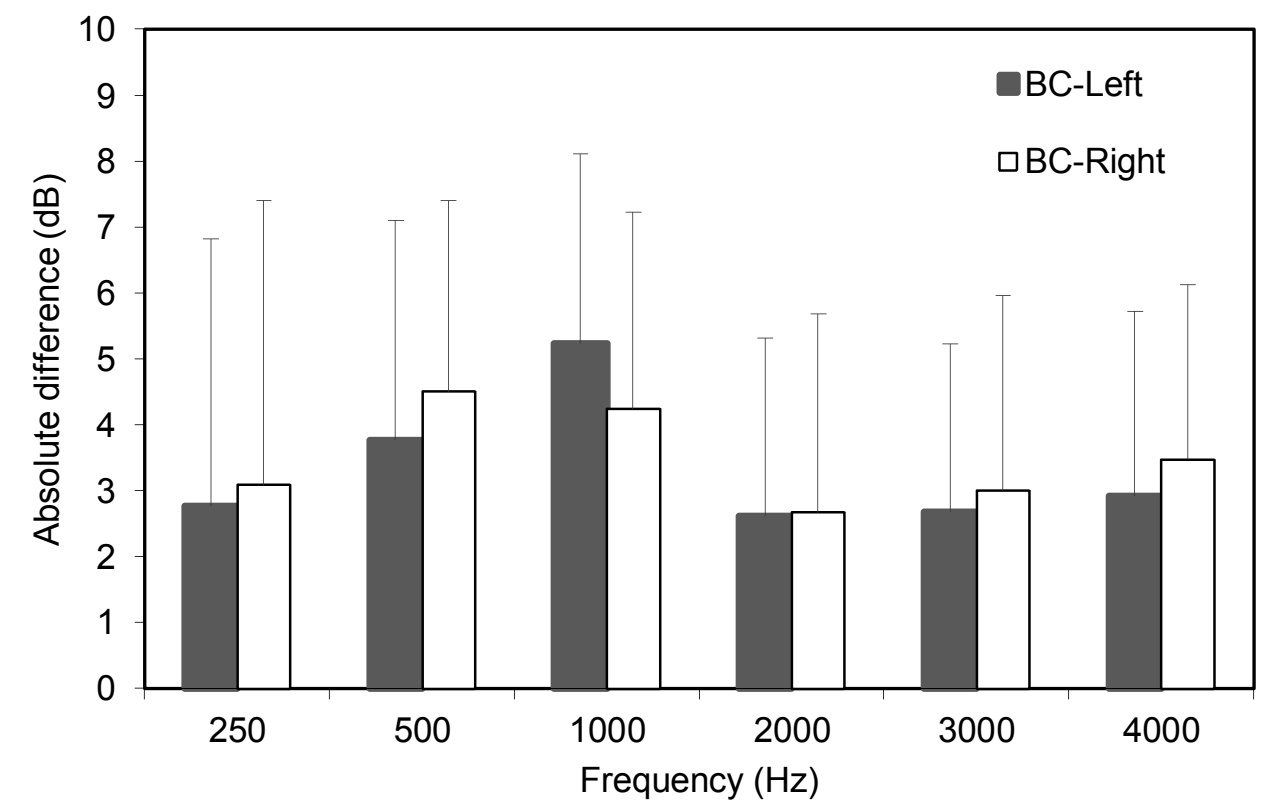

Figure 4. Average absolute difference between bone conduction thresholds recorded in the natural and audiometric booth environment (error bars $=1$ SD)

Comparison of air- and bone-conduction thresholds obtained in the natural and audiometric booth environments revealed no statistically significant differences (Paired Samples T-test; $p>0.01$ ) except at $8000 \mathrm{~Hz}$ in the left ear for air conduction $(p=0.006)$. That one exception was not clinically significant. Differences were within 0 to $5 \mathrm{~dB}$ of each other for $94 \%$ of thresholds. Table 5 shows threshold correlation coefficients between 0.92 and 0.99 for air conduction and 0.63 and 0.97 for bone conduction in the natural and audiometric booth test environments.

The number of subject responses to pure-tone presentations and the average reaction time and standard deviation of these were also compared between the natural and audiometric booth environments and showed no significant difference (Paired Samples T-test; $p>0.01$ ). 
Table 5. Pearson correlation coefficients for air and bone conduction thresholds recorded in the natural and audiometric booth environment

\begin{tabular}{|c|c|c|c|c|c|c|c|c|}
\hline Freq $(\mathrm{Hz})$ & 250 & 500 & 1000 & 2000 & 3000 & 4000 & 6000 & 8000 \\
\hline \multicolumn{9}{|c|}{ AC Threshold Correlation (Natural \& Booth) } \\
\hline Left & .93 & .96 & .97 & .98 & .99 & .99 & .98 & .97 \\
\hline Right & .92 & .97 & .98 & .98 & .98 & .98 & .98 & .96 \\
\hline \multicolumn{9}{|c|}{ BC Threshold Correlation (Natural \& Booth) } \\
\hline Left & .73 & .90 & .89 & .97 & .97 & .97 & & \\
\hline Right & .63 & .87 & .92 & .97 & .96 & .96 & & \\
\hline
\end{tabular}

\section{DISCUSSION}

Ambient noise may reduce the specificity of audiometric testing (Bromwich et al. 2008). In the absence of an audiometric booth, the management and the monitoring of background noise are essential for accurate evaluation of hearing thresholds (Swanepoel, Clark et al. 2010; Swanepoel, Olusanya \& Mars, 2010). We evaluated the performance of an audiometer employing passive attenuation using insert earphones covered by circumaural earcups coupled with real-time monitoring of environmental noise for air-conduction and boneconduction threshold measurement in a natural environment. Double transducer attenuation using insert foam plugs and circumaural earcups produces a significant increase in ambient noise attenuation that may actually exceed typical attenuation for transportable sound booths (Berger, Kieper \& Gauger, 2003; Franks, 2001). Results of the current study confirmed statistically and clinically equivalent hearing thresholds as measured in a natural environment versus a sound-treated booth. 
Air-conduction thresholds measured in the natural and standard audiometric booth corresponded within typical $5 \mathrm{~dB}$ or less test-retest limits for thresholds measured in a sound booth (Stuart et al. 1991; Smith-Olinde et al. 2006; Margolis et al. 2010; Swanepoel, Mngemane et al. 2010; Swanepoel \& Biagio, 2011). Average absolute air-conduction threshold differences for the current study $(2.7 \pm 3.1 \mathrm{~dB})$ were within previously reported average test-retest absolute difference values $(3.6 \pm 3.9 \mathrm{~dB}$ and $3.5 \pm 3.8 \mathrm{~dB})$ for the same audiometer (Swanepoel, Mngemane et al. 2010; Swanepoel \& Biagio, 2011).

In the current study, $95 \%$ of threshold comparisons were within $5 \mathrm{~dB}$ or better compared to $88 \%$ for test-retest measures in a sound booth environment previously reported for this audiometer (Swanepoel, Mngemane et al. 2010). The slightly better correspondence between air-conduction thresholds recorded in the natural and sound booth environments compared with the test-retest differences reported by Swanepoel, Mngemane et al. (2010) may partly be attributed to the omission of $125 \mathrm{~Hz}$ as a test frequency in the current study. This low test frequency showed a larger test-retest discrepancy than the other frequencies in the Swanepoel, Mngemane et al. (2010) study. Overall the correlation between airconduction thresholds recorded in a sound booth environment and a natural environment was very high (>.92) across all frequencies.

The average absolute difference in bone-conduction thresholds recorded in the natural and audiometric booth $(3.4 \pm 4.3 \mathrm{~dB})$ was within previously reported bone-conduction test-retest differences (Laukli \& Fjermedal, 1990; Margolis et al. 2010; Swanepoel \& Biagio, 2011). The average absolute test-retest variability for this same audiometer previously reported in a small group of 10 normal-hearing subjects was $7.1 \pm 6.4 \mathrm{~dB}$. Laukli and Fjermedal (1990) reported bone-conduction test-retest standard deviation variability between 3.2 and $4.8 \mathrm{~dB}$ across 250 to $4000 \mathrm{~Hz}$ in a small sample of normal-hearing adults. Similarly, Margolis et al. (2010) reported an average absolute test-retest difference for bone-conduction thresholds of $4.1 \pm 3.8 \mathrm{~dB}$ across frequencies. Overall, $97 \%$ of bone-conduction thresholds corresponded 
within $10 \mathrm{~dB}$ between the two environments, which is within accepted bone-conduction testretest variability (Roeser \& Clark, 2007). Bone-conduction test-retest thresholds are more susceptible to variability compared with air-conduction thresholds owing to several factors including differences in static force applied, location of the bone vibrator, functional state of the middle ear, position of the lower jaw, and distortion of bone vibrators at lower frequencies (Stenfelt \& Goode, 2005; Stuart et al. 1991).

Owing to the advancing age of the population assessed, hearing loss greater than $25 \mathrm{~dB}$ (average of 500, 1000, 2000 and $4000 \mathrm{~Hz}$ ) was present in $59 \%$ of ears. Since ambient noise would be more likely to affect threshold determination in the normal ranges $(0-25 \mathrm{~dB} H \mathrm{HL})$ the validity of thresholds in the natural and sound booth environments was compared for normal and abnormal hearing categories (Table 3). Similar threshold correspondence and absolute threshold differences were however obtained from the two environments for air- and bone-conduction testing. Thresholds for air conduction corresponded within $5 \mathrm{~dB}$ in $94.1 \%$ compared with $94.9 \%$ for normal and elevated hearing thresholds respectively. For boneconduction thresholds, correspondence was within $10 \mathrm{~dB}$ in $96.7 \%$ compared with $96.9 \%$ for normal and elevated hearing thresholds respectively.

This study provides evidence that valid diagnostic air-conduction and bone-conduction puretone hearing thresholds can be recorded using a mobile audiometer without a sound booth or sound-treated room. Using insert earphone and circumaural earcup attenuation, with realtime monitoring of noise, provides passive control of environmental noise and offers on-going active evaluation of transient extraneous interference. Our data support the possibility of conducting valid diagnostic pure-tone audiometry outside a regular clinic setup. Active noise monitoring provides a measure of quality control. Furthermore, the system can be set to monitor noise levels according to the average attenuation provided by the test setup in a typical group of subjects as opposed to double attenuation values previously reported (Berger, Kieper \& Gauger, 2003). By employing these attenuation levels, the software can be 
programmed to monitor ambient noise levels across octave or interactive levels, according to standards for audiometric test environments (e.g. ANSI S3.1-1999(R2008)). This allows the clinician to monitor the noise that may be influencing threshold testing at specific frequencies and intensities. For valid bone-conduction testing outside an audiometric booth, occlusion of the non-test ear is required. Deeply inserted insert earphones can minimize the occlusion effect at low frequencies $(250-1000 \mathrm{~Hz})$ to a clinically insignificant level (Stenfelt \& Goode, 2005). Achieving deep insertion of the insert earphone may however be challenging and in the present study $24.5 \%$ of subjects required removal of cerumen by the clinician before testing.

\section{CONCLUSION}

Environmental noise has historically been controlled during diagnostic audiometry by using audiometric booths that are certified annually. Advances in technology may however offer alternate ways of performing diagnostic audiometry while simultaneously extending testing sites beyond the confines of the conventional audiometric booth setting. The current study demonstrated that valid diagnostic air-conduction and bone-conduction audiometry can be conducted on elderly patients at their retirement facilities without the use of a sound booth or sound-treated room using insert earphones covered by circumaural earcups with integrated active monitoring of ambient noise levels. Continual monitoring of ambient noise during testing provides an effective measure of quality control. The possibility of performing diagnostic audiometry with patients unable to attend clinics for any number of reasons extends access to valid evaluations outside of a conventional clinic. Of greater significance and with further-reaching implications, this type of technology permits the delivery of diagnostic audiometry services to low- and middle-income countries where sound booths are a scarce luxury and diagnostic testing is impossible as a result (Swanepoel, Clark et al. 2010; Swanepoel, Olusanya \& Mars, 2010). With more than $80 \%$ of people with hearing loss globally residing in developing countries, these new advances in technology may lead to a broadening of access to diagnostic hearing health care services in these communities (WHO, 
2006; Swanepoel, Clark et al. 2010; Swanepoel, Olusanya \& Mars, 2010). Access to audiometry is a global concern (Margolis \& Morgan 2008; Swanepoel, Clark et al. 2010, Swanepoel \& Hall, 2010) for which the continued advances in technology must be harnessed to ensure that people with hearing loss everywhere have access to services.

\section{DECLARATION OF INTEREST}

The authors report no conflicts of interest and state that they alone are responsible for the content and writing of this article. Data from this study were presented at the XXXI World Congress of Audiology on May 3, 2012 in Moscow and at the Coalition for Global Hearing Health Conference on May 30, 2012 in Pretoria, South Africa.

\section{REFERENCES}

ANSI S3.1-1999 (R2008). 1999. Maximum permissible ambient noise levels for audiometric test rooms. American National Standards Institute, New York.

Arlinger, S.D. 1986. Sound attenuation of TDH-39 earphones in a diffuse field of narrowband noise. J Acoust Soc Am, 79, 189-191.

ASHA 2005. Guidelines for manual pure-tone threshold audiometry. Am Speech-LanguageHearing Ass. www.asha.org/policy (accessed 14 September 2012).

Berger, E.H. 1983. Laboratory attenuation of earmuffs and earplugs both singly and in combination. Am Ind Hyg Assoc J, 44, 321-329.

Berger, E.H. \& Killion, M.C.1989. Comparison of the noise attenuation of three audiometric earphones, with additional data on masking near threshold. J Acoustic Soc Am, 4, 13921403.

Berger, E.H., Kieper, R.W. \& Gauger, D. 2003. Hearing protection: surpassing the limits to attenuation imposed by bone-conduction pathways. J Acoust Soc Am, 114, 1955-1967. Bromwich, M.A., Parsa, V., Lanthier, N., Yoo, J. \& Parnes, L.S. 2008. Active Noise Reduction Audiometry: A Prospective Analysis of a New Approach to Noise Management in Audiometric Testing. The Laryngoscope, 118, 104-109. 
Clark, J.L. \& Roeser, R.J. 1988. Three Studies Comparing Performance of the ER-3A Tubephone with the TDH-50P Earphone. Ear and Hearing, 9, 268-274.

Dean, M.S. \& Martin, F.N. 2000. Insert earphone depth and the occlusion effect. Am J Audiol, 9, 131-134.

Frank, T., Greer, A.C. \& Magistro, D.M. 1997. Hearing Thresholds, Threshold Repeatability, and Attenuation Values for Passive Noise-Reducing Earphone Enclosures. Am Ind Hyg Ass $J, 58,772-778$.

Frank, T. \& Williams, D.L. 1993. Ambient noise level in audiometric test rooms used for clinical audiometry. Ear and Hearing, 14, 414-422.

Frank, T. \& Williams, D.L. 1994. Ambient noise level in industrial audiometric test rooms. Am Ind Hyg Ass J, 55, 433-437.

Frank, T. \& Wright, D.C. 1990. Attenuation provided by four different audiometric earphone systems. Ear and Hearing, 11, 70-78.

Franks, J.R. 2001. Hearing Measurement. Chapter 8 in Goelzer, B., Hansen, C. and Sehrndt, G. (eds), World Health Organisation, Federal Institute for Occupational Safety and Health, Dortmund, pp.183-232.

ISO 389-2. 1994. Acoustics - Reference zero for the calibration of audiometric equipment Part 2: Reference equivalent threshold sound pressure levels for pure tones and insert earphones. Geneva: International Organization for Standardization.

Laukli, E. \& Fjermedal, O. 1990. Reproducibility of Hearing Threshold Measurements: Supplementary Data on Bone-conduction and Speech Audiometry. Scand Audiol, 19, 187190.

Margolis, R.H., Glasberg, B.R., Creeke, S. \& Moore, B.C.J. 2010. AMTAS: Automated method for testing auditory sensitivity: Validation studies. Int J Audiol, 49, 185-194 Margolis, R.H. \& Morgan, D.E. 2008. Automated pure-tone audiometry: An analysis of capacity, need, and benefit. Am J of Audiol, 17,109-13. 
OSHA (1983). Occupational Noise Exposure; Hearing Conservation Amendment; Final Rule. Occupational Safety and Health Administration, 29CFR1910.95 Fed. Regist. 48(46), 9738-9785.

Roeser, R.J. \& Clark, J.L. Pure-tone tests. Roeser, Valente, Hosford-Dunn (eds.) Audiology Diagnosis. New York: Thieme, pp 238-260.

Smith-Olinde, L., Nicholson, N., Chivers, C., Highley, P. \& Williams, D.K. 2006. Test-retest reliability of in situ unaided thresholds in adults. Am $\mathrm{J}$ of Audiol, 15, 75-80.

Stenfelt, S. \& Goode, R.L. 2005. Bone-conducted sound: Physiological and clinical aspects. Otol Neurotol, 26, 1245-1261.

Stuart, A., Stenstrom, R., Tompkins, C. \& Vandenhoff, S. 1991. Test-retest variability in audiometric threshold with supraaural and insert earphones among children and adults. Audiology, 30, 82-90.

Swanepoel, De W. \& Biagio, L. 2011. Validity of Diagnostic Computer-Based Air and Forehead Bone conduction Audiometry. J of Occupational and Environmental Hyg, 8, 210214.

Swanepoel, De W., Clark, J.L., Koekemoer, D., Hall 111, J.W., Krumm, M., et al. 2010. Telehealth in audiology: The need and potential to reach underserved communities. Int $J$ Audiol, 49, 195-202.

Swanepoel, De W. \& Hall 111, J.W. 2010. A Systematic Review of Telehealth Applications in Audiology. Telemed J e-Health, 16, 1-9.

Swanepoel, De W., Olusanya, B.O., \& Mars, M. 2010. Hearing health-care delivery in subSaharan Africa - a role for tele-audiology. J of Telemed \& Telecare, 16, 53-56.

Swanepoel, De W., Mngemane, S., Molemong, S., Mkwanazi, H. \& Tutshini, S. 2010. Hearing Assessment-Reliability, Accuracy, and Efficiency of Automated Audiometry. Telemed J e-Health, 16, 557-563.

WHO 2006. Deafness and hearing impairment. Geneva: World Health Organization. http://www.who.int/mediacentre/factsheets/fs300/en/index.html (accessed 13 May 2012). 